\title{
Using AHP as a Diagnostic Tool to Reveal an Audiences Authentic Needs and Develop a Strategy, to Achieve Competitive Advantages.
}

\author{
David B. Brauer \\ Durham University Business School \\ Durham University \\ Durham, England, UK \\ E-mail: d.b.brauer@,durham.ac.uk
}

\begin{abstract}
Organizations of all types need to address a common problem of limited capital. This creates an additional burden that the decision-makers of organizations have to manage. Key decisions need to result in the best outcomes for the use of the capital. Organizations that do poorly with these decisions will increase their hazard of mortality. They need to use tools that will increase the positive outcomes of their decisions.

Most often organizations view the criteria that their stakeholders value as known attributes. Some of the most notable failures of businesses in the past decades can be directly linked with organizations not knowing the importance that their key stakeholders placed on certain attributes. Kodak developed a digital camera in 1975 and did not assess the value this technology would have for its customers. In 1985, Coca-Cola thought by expanding their niche width to include "New Coke", success would follow. They did not foresee that the audience would not see this as authentic Coke.

This paper addresses the issues organizations have identifying the selection criteria, as well as the magnitude of the criteria. Audiences have the final decision of which products they will consume. My study will show how the Analytic Hierarchy Process, herein after referred to as AHP, can be used as a diagnostic tool to reveal the attributes that an audience views as vital in meeting their needs and having the product or service viewed as authentic. The results of the AHP can then be used by the organization to develop a strategy that should increase the organization's competitive advantages.
\end{abstract}

Keywords: Analytic Hierarchy Process, Audience, Authenticity, Category Spanning, Competitive Advantage, Niche Width, Organizational Ecology, Resource Partitioning. 
1. Introduction Organizations of all types need to address a common problem of limited capital. This creates an additional burden that the decision-makers of organizations have to manage. Key decisions need to result in the best outcomes for the use of capital. Organizations that do poorly with these decisions will increase their hazard of mortality. They need to use tools that will increase the positive outcomes of their decisions.

Graduate business schools are not dissimilar in this respect to other organizations. This study will address the increase in the hazard of mortality of AACSB graduate business schools in the United States due to the globalization of education, increased competition in the form of online institutions of education, diminishing resources and support due to the lack of government sponsorship and a faltering economy. Survival is not guaranteed, if schools cannot attract high-quality students in sufficient numbers, their hazard of mortality will increase and they may not survive. The purpose of the study is to see if a strategy of sustainability might provide a competitive advantage.

I was motivated to do this work because I am interested in the theories and theory fragments of organizational ecology, AHP, and strategies of sustainability and their possible interactions. Currently I am working on these issues in preparation to defend my dissertation for my PhD at Durham University Business School (UK).

My main question is, "How and why can a strategy of sustainability be used for AACSB accredited graduate business schools in the United States to gain competitive advantage?" This study is important because schools will be able to see if they are expending their resources in an efficient manner to attract human and financial capital. They will be able to see the selection criteria that are important to their audience and the magnitude of importance using an adaptation of the AHP. This will decrease their hazard of mortality.

With this tool they will be able to plug in (i.e. a strategy of sustainability, or customer engagement requirement) and unplug different criteria to make a more valid assessment. (This is needed to gain audience acceptance, to gain legitimation, and to create socially constructed authenticity. Over time authenticity can wane and ebb.) When this study is completed a clear understanding of the relationship of authenticity, time, and sustainable competitive advantages and how they are interrelated should be revealed, as well as the importance AHP has in this role.

\section{Literature Review}

Globalization, ever-increasing technology, and limited resources contribute to increased competition which can result in increased hazard of mortality. In most cases, inertia, is not a valid action for survival. The Icarus Paradox is that so many organizations are blinded by their own success that they believe continuation of their efforts will lead to future success ( Singh, 2012). Probert said, in a 1997 article, "company should focus their efforts, resources, and investments on technologies that are important to them." I disagree. All capital should be focused on what is important to the audience.

Graduate business schools, are no different than any other organization, regarding the competitive pressures they face. Institutions of higher education are not immune from an increased hazard of mortality. Almost a third of all educational institution's financial statements are weaker than they were several years ago and at the same time debt service and expenses have increased. Institutions with large endowments 
are fine but are also the minority. The larger the stock of organizational capital an institution has, the more able it is to survive bad decisions.

"The factors determining success for universities is not well studied." (Chen and Hsieh, 2008). An institution's fitness in relation to other institutions in the same niche is referred to as relative fitness. Niche, was a concept developed by Charles Elton in 1927, describing the role of a group in an environment. The actual appeal of the offering is dependent upon the intrinsic appeal of that offering. "The greater the appeal usually correlates to the greater fitness and organization hats, the hazard of mortality declines with greater fitness." (Hannan, Carroll and Pólos, 2003).

When an institution's offering conforms to the perceptions of the audience regarding similar offerings, then the offering's authenticity is legitimized. The authenticity of offerings can result in a competitive advantage. Michael Porter has three methods for creating sustainable competitive advantages; cost, differentiation, or focusing on a unique market niche (Porter, 2008). A competitive advantage is unique for each institution. Its authenticity and makeup is the result of the perceptions of its audience.

In the majority of work in organizational ecology the relationship of time, authenticity and competitive advantage is left undiscussed. There is discussion of the relative importance of the various criteria that an audience uses to evaluate an organization. To date little work has been done on the magnitude of the differences of the criteria. Institutions need to have customer focused agility training to be able to see opportunities before the competitors do, so that the opportunities do not become threats (Ning, 2012).

The changes in perceptions of the audiences can be caused by several factors. "User tastes and preferences change and evolve over time. Shifting trends in the community, the arrival of new products and even changes in user social networks, influence the rating behavior." (McAuley and Leskovec, 2013). AHP can be used as a tool to help university administrators decide on the strategy for the best use of their capital. Since AHP is based on a premise that reality is based on perceptions; it provides a bridge to organizational ecology. AHP places numerical values on concepts that are abstract, these can be used to make conclusions and arrive at a meaningful strategy (Saaty, 1998). AHP can be adapted for individual purposes.

"There are always multiple paths. Theories of change should not just be outcome focused or seen primarily as extensions of the past, but rather, change can be viewed as a creation and exploration of alternative realities" (Lord, Dinh, and Hoffman, 2013). AHP gives us the flexibility to explore the alternative realities.

\section{Hypotheses/Objectives}

Hypothesis one: If graduate business schools pursue a strategy of sustainability then they will gain competitive advantages.

Hypothesis two: The more complete the pursuit of sustainability by the graduate business school the greater the advantages will be.

Hypothesis three: The higher the ranking of the graduate business school the less the impact of those competitive advantages will be as they are already a highly desired institution.

Hypothesis four: The greatest impact of the pursuit of a strategy of sustainability will be for those schools that find themselves in the second tier and lower in the rankings. 


\section{Research Design/Methodology}

In order to attack the problem it is essential to find out what is important to the audience. What criteria do they use to choose a product or similar products? You need to find out what the magnitude of each of those selection criteria are in relation to one another. What steps have universities taken to be viewed as sustainable and has it resulted in any increased attention from the audience?

What are the factors? Determined by a qualitative study and literature review they are: Cost, fellowships available, loans available, ranking, GMAT average, GPA average, distance between school and permanent residents, sustainability, previous work experience, in-state or out-of-state, location of school, environment of the campus, starting salary upon graduation, legacy, did a mentor recommended, length of the program, program availability, career opportunities, type of accreditation, future education potential, alumni networking opportunities, strength of alumni network, diversity, international study, core values of the University.

How to prioritize them? To get the true picture you need to do a pairwise comparison of the relevant criteria in order to determine their weighted priority. This can be done utilizing the modified AHP to get to aggregated priority of the interviewed audience.

\section{Steps to complete the study:}

Step one: Have MBA students at AACSB accredited schools in the United States complete qualitative interviews to determine selection criteria used by the audience. Using viable selection criteria an adaptive model of the Analytic Hierarchy Process will be used to survey students to determine a weighted preference of criteria in the selection process. This will determine the magnitude of importance of criteria when students are choosing which school to attend. This will be done by pairwise comparisons of the pertinent selection criteria when choosing a graduate business school. The scores and ranks will then be aggregated.

Step two: Concurrently fuzzy sets will be developed for graduate business schools measuring authenticity of those certain criteria. This will be done through quantitative surveys of the school.

Step three: Combining the two quantitative results one will be able to determine the efficacy of a strategy using certain criteria. Then other criteria can be plugged in while others are unplugged to test new or additional criteria.

\section{Data/Model Analysis}

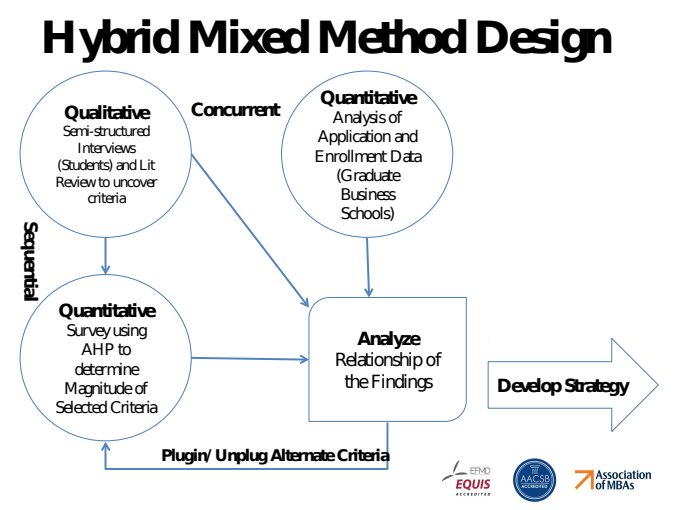

International Symposium of 


\section{Limitations}

Potential issues and limitations are gaining access to students to take the survey. A second potential issue may be getting current admissions data at graduate business schools.

\section{Conclusions}

The relationship between authenticity, time and competitive advantage cannot be clearly understood without the use of AHP. This study will plug in, sustainability, as an audience selection criteria for institutions of higher education. The results will show the magnitude of importance sustainability has to other criteria and when compared with other results, it will lead to a conclusion as to whether sustainability can be a competitive advantage for graduate business schools. This is a unique use of AHP to be used as a diagnostic tool in order to compare and contrast the use of alternate criteria in a multiple criteria decision making problem.

Future studies could include any industries and any organizations who seek to utilize the efficiencies that AHP can illuminate. This study creates a unique and close relationship between AHP and organizational ecology which has not been explored before.

\section{Key References}

Chen, Y.G. \& Hsieh, P.(2008). A service-based view of Porter's Model of Competitive Advantage. International Journal of Management, 25, 38-53.

Hannan, M.T., Carroll, G.R., \& Pólos, L. (2003). The Organizational Niche. Sociological Theory, 21, 309-340.

Hannan, M.T., \& Freeman, J. (1989). Organizational Ecology. Cambridge, MA: Harvard University Press.

Negro, G. and Leung, M.D. (2013). Actual and Perceptual Effects of Category Spanning, Organization Science, 24, 684-696.

Saaty, T.L.(1977). A scaling method for priorities in hierarchical structures. Journal of Mathematical Psychology, 15, 59-62. 